\title{
The law tries to decide whether whooping cough vaccine causes brain damage: Professor Gordon Stewart gives evidence
}

\author{
BY A LEGAL CORRESPONDENT
}

The first English case to try the issue of whether whooping cough vaccine can cause brain damage, now in its sixth week in the High Court, took a dramatic turn last week when the legal aid authorities unsuccessfully applied for a month's adjournment. The father of 16 year old Johnnie Kinnear, who alleges that his brain damaged son was a normal child before he had the routine vaccination against diphtheria, pertussis, and tetanus at 14 months, has been given until 16 May to "show cause" why his legal aid certificate should not be discharged following evidence by the boy's mother about the circumstances surrounding his vaccination. Her evidence is not supported by the available medical records, and the legal aid rules stipulate that the legal aid committee shall discharge a certificate where, as a result of information which has come to its knowledge, it considers that "the assisted person no longer has reasonable grounds for taking, defending or being a party to the proceedings, or for continuing to do so," or that "it is unreasonable in the particular circumstances that the assisted person should continue to receive legal aid."

If the legal aid committee decides to withdraw funding for the case, Johnnie Kinnear's father, Michael, will have a further 14 days in which to appeal to the area committee. The adjournement was sought to save the legal aid fund paying for a further month in court for the Kinnears's barristers, solicitors, and expert witnesses, only to have the case collapse if legal aid is withdrawn. But the judge ruled that the trial should go ahead in the interim. He said he hoped some means could be found whereby the legal aid authorities could continue to fund the case because of the importance of resolving the central issue of whether or not whooping cough vaccine can cause brain damage, which has already taken up most of the first five weeks of the trial, and on which more than 200 other pending claims hinge. But the wording of the legal aid regulations makes it doubtful that aid can be continued irrespective of the merits of the individual case for the sake of clarifying an issue for future cases.

If the case continues Mr Justice Stuart Smith will have to decide whether the vaccine caused Johnnie Kinnear's brain damage and whether Dr Joshua Stein, the North West Thames Regional Health Authority, or both, were negligent in giving it. But most of the court's time will be taken up in sifting expert evidence on the issue of causation. The vaccine's manufacturers, the Wellcome Foundation, deny that there is any valid statistical evidence that it causes brain damage.

Writs in the case were issued against four defendants: the Department of Health and Social Security and the Wellcome Foundation as well as Dr Stein and the health authority. But legal aid to take the manufacturers and the DHSS to court was turned down, and the claim has proceeded only against the doctor and the North West Thames Health Authority. The Wellcome Foundation, however, is taking part in the trial at its own request not as a defendant but as a "party interested." In fact, the company's lawyers are conducting the defence as far as the issue of causation is concerned, even though, since it is no longer a defendant, Wellcome cannot be ordered to pay damages. This is the first time in Britain that a drug company has defended the safety of one of its products in a full court hearing. The manufacturers did not feature in the first British vaccine damage case, heard in Scotland last year, in which 9 year old Richard Bonthrone lost his claim for damages against Fife Health Board, a doctor, and a health visitor.

\section{Professor Stewart's evidence}

Most of the first few weeks have been taken up with the evidence of Professor Gordon Stewart, the first of what promises to be a parade of expert witnesses and a leading figure in the pertussis vaccine controversy. Opening the case for Johnnie Kinnear, Julian Priest QC took Professor Stewart, now a temporary consultant to the World Health Organisation, through the background to whooping cough vaccination and the literature on adverse reactions. Professor Stewart said that the vaccine in current use was prepared from whole cells, growing the organism of whooping cough in a suitable bacteriological medium and then taking the entire suspension of living bacteria, killing them, adjusting to a certain density, and injecting the whole preparation into children.

Early reports of adverse effects went back to 1933, when Madsen reported two sudden deaths in Denmark, and the sudden deaths of identical twins from delayed anaphylactic shock were reported in the United States in 1946. In 1948 Byers and Moll reviewed 15 cases of encephalopathy after pertussis immunisation. Regression or failure of further development occurred in several instances.

Ström published the results of his investigation into vaccine reactions in Sweden in the $B M F$ in 1960. In 215000 vaccinated children there were four deaths and nine children showing severe cerebral sequelae. The Swedish Royal Medical Board appointed a special committee to examine Ström's cases, which were drawn from a questionnaire sent to hospital departments and child welfare centres, covering the period 1955-8. The committee concluded that the proved incidence of brain damage was 1 in 50000 . In a later study of children born between 1962 and 1964 Ström estimated the incidence of gross destructive encephalopathy at 1 in 170000 , and brain damage less than destructive at 1 in 34000 . Sweden discontinued the vaccine in 1978.

Professor Stewart said that, no matter how scrupulously the vaccine was prepared, one could not avoid including toxic products. Also, it was impossible to guarantee uniformity in dosage because the bacteria may clump with the result that more bacteria are injected. With sudden deaths after immunisation usually nothing was found at necropsy. He referred to a 1983 paper by Corsellis and others, a neuropathological review of whooping cough immunisation. The cases of 29 children whose deaths since 1960 had been thought to have a possible relationship to the vaccine and on whom a necropsy had been done were analysed, and of the 18 dying within a short time of vaccination, in only two were specific features noticed. Professor Stewart said that in his view by the nature of the reaction the change had to be non-specific; it was an indirect effect of hypoxia and poor circulation.

Dr A H Griffith, formerly of the Wellcome Foundation, wrote in the $B M \mathcal{F}$ in 1978 that out of 15 million doses of pertussis vaccine distributed in the UK from 1964 to 1977 , only six deaths, six neurological reactions with sequelae, and 17 convulsions without sequelae had been reported to the company, a total adverse 
incidence rate of 1 in 652174 . Between 1965 and 1975, however, roughly the same period as dealt with in the Griffith's paper, 344 awards were made under the Vaccine Damage Payments scheme for pertussis vaccine, said Professor Stewart.

Mr Priest commented that it was illogical that Mr Justice Stuart Smith had to try the issue whether under any circumstances in any child the vaccine could cause damage when the vaccine damage tribunal had clearly proceeded on the assumption that it could do so. But the fact that those awards were made could not pre-empt his lordship's decision.

Professor Stewart moved on to the Public Health Laboratory Service seven year survey of disorders attributed to vaccine in the North West Thames region, reported by Pollock and Morris in the Lancet in 1983. The study found that anaphylaxis and collapse, convulsion, and neurological disorder were reported most often after the triple vaccine against diphtheria, tetanus, and pertussis (DTP). This disparity was thought to be due in part to adverse publicity about pertussis. An alternative method of study based on the hospital activity analysis was therefore used. The researchers concluded that the neurological disorders reported as reactions to DTP were too widely divergent to suggest a common aetiological agent; taken individually, since such disorders are known to occur in unvaccinated children, none could with any confidence be attributed to the vaccine.

They added: "This study did not support the claim that DTP produces a syndrome, arising in 1 in 17000 to 1 in 52000 vaccinated children, whose main elements are the occurrence in a previously healthy child of continuous screaming, collapse, and convulsion after the injection soon followed by arrest of mental development and by varying degrees of physical handicap. If a striking syndrome of this sort exists, instances of it would probably have been discovered in the North West Thames region, where more than 400000 injections of DTP were given in the seven years covered by the study. We cannot rule out the possibility that some vaccines may on rare occasions cause brain damage, but no convincing evidence of this has appeared during our study."

Professor Stewart said there was a distinct contradiction between this conclusion and those of almost everybody else who up to that point had systematically examined the problem. Although the scale of surveillance was impressive, the data showed many inconsistencies. An estimate based on vaccine damage tribunal awards for children presumably brain damaged by pertussis vaccine is that brain damage occurred between 1958 and 1981 with a frequency of about 1 in 25000 children who received pertussis vaccine.

\section{Criticism of National Childhood Encephalopathy Study}

Mr Priest asked Professor Stewart about the National Childhood Encephalopathy Study, a nationwide case control retrospective study carried out between July 1976 and July 1979 to assess the risk of serious neurological disorders following immunisation and to identify factors that might cause or dispose to such disorders. That study estimated the attributable risk of permanent brain damage after DTP as 1 in 310000 doses, or around 1 in 100000 children. Professor Stewart commented that by 1976 it was becoming apparent that there were contraindications to pertussis vaccine so from that point vaccine was rarely given to children with gross contraindications, and therefore the findings of this survey were bound to be different from the findings of earlier years.

He added that he was a little critical of the admission criteriachildren between 2 and 36 months admitted to hospital with certain conditions or signs. One of the conditions was a convulsion having a total duration of more than half an hour, when most lasted only about 30 seconds. The most common incident in the studies was the short convulsion or series of short convulsions. In the series of cases reported to him and those reported to the Meade Panel (an advisory committee to the Committee on Safety of Medicines (CSM) which looked at cases provided by the Association of Parents of Vaccine Damaged Children) something like one third would not have qualified for admission to the encephalopathy study. The survey was a pick up of acute cases, but it was certainly the best thing of its kind, not only in Britain but anywhere at present. What was important was the finding that there was a highly significant association between acute neurological illness and prior DTP and no such association with vaccines against only diphtheria and tetanus. (DT).

Earlier, the Meade Panel had concluded: "Pertussis vaccine almost certainly gives rise to convulsions in some children and there is probably a small risk of permanent neurological impairment and even death." They estimated this "small risk" at 1 in 53000 , said Professor Stewart.

The Kulenkampf study of children believed to have reacted adversely to DTP attracted a lot of attention when it was published in 1974, he said. These were children seen between 1961 and 1972 at the Hospital for Sick Children at Great Ormond Street. The conclusion was that "the clustering of complications in the first 24 hours after inoculation suggests a causal rather than a coincidental relation." Professor Stewart discussed his own report to the DHSS on suspected adverse reactions to pertussis vaccine in relation to the efficacy and the risks of whooping cough over the period 1964 to 1982. This was an assessment of 201 cases in which the analysis was reasonably complete, all with a diagnosis of brain damage. Some had come from the Association of Parents of Vaccine Damaged Children and some from the CSM; 111 had contraindications to pertussis vaccinations, and in 91 cases consultants had attributed brain damage to pertussis vaccine.

\section{Protocol of encephalopathy study}

Cross examined by Anthony Machin QC, leading counsel for the Wellcome Foundation, Professor Stewart agreed that the encephalopathy study was the only case control study of whooping cough vaccine and brain damage, that he had been interested in the pertussis vaccine controversy for many years, and that he was fully familiar with the protocol of the encephalopathy study. Asked whether the children in the study had to remain in hospital for any particular time, Professor Stewart replied that the methodology said 15 days but that he accepted the view of Professor Miller (who oversaw the study) that there was some flexibility about this.

$\mathrm{Mr}$ Machin asked Professor Stewart to read the part of the blue book which required a child to have been in hospital for 15 days. Professor Stewart read: "the results of investigations and the clinical progress or condition of the patient at discharge or 15 days after admission, whichever was the sooner." To the repeated question, he replied that there was no statement that the child must remain for 15 days, but this was the usual interval because it stated: "whether or not they had 'residual' problems recorded at discharge or at 15 days after admission." In answer to Mr Machin's question that it was obvious, was it not, that a child who went into hospital and came out after two days would still qualify for inclusion, Professor Stewart replied: “I don't know about that; I just don't know about that." He said he had always thought that it had to be 15 days, though with some flexibility.

Professor Stewart agreed that he had given evidence in the form of depositions in some 12 to 15 American cases. On 5 May 1983 he had given a deposition in a case called Tom. Mr Machin asked him whether he had said in the course of giving the deposition that the encephalopathy study took only children who were in hospital 15 days later. He replied that if it was recorded in the deposition and signed by him he must have said it. He said he had seen a letter to the $B M \mathcal{J}$ from Professor Miller and Dr Euan Ross in response to a televison programme on which he had appeared on 6 May 1983, which read: "[Professor Stewart] stated incorrectly that the study included only children with convulsions lasting 30 minutes or more and who remained in hospital for at least 15 days.... although admission to hospital was a criterion for entry into the study, the duration of stay in hospital was not. ..."

Mr Machin drew Professor Stewart's attention to a statement in his report to the DHSS in October 1983: "But the encephalopathy study is by its design restricted to children aged two to 36 months admitted to hospital ... and still in hospital 15 days later." Professor 
Stewart said he had made a mistake and it should be corrected. A letter published in the American fournal of Epidemiology in 1984 in which he had made the same criticism had been written some time before, even before his report. He said that until he was asked these questions he had never realised he had made an untrue statement in his letter and in the DHSS report.

Mr Machin asked Professort Stewart whether he had ever thought that a child had to be admitted to hospital within a particular time of the onset of its illness. Professor Stewart replied that he did not think the protocol included that statement. $\mathrm{Mr}$ Machin asked him what the basis was for his statement in his deposition in the Kendricks case, one of the American cases, that "the child had to be admitted to hospital within one month of the onset of the incident." Professor Stewart said that was his belief. $\mathrm{Mr}$ Machin suggested that he was carelessly misrepresenting the position or had just not bothered to read the encephalopathy study. Professor Stewart replied that it would appear that he had been both careless and mistaken so far as the protocol was concerned.

$\mathrm{He}$ also agreed that he had criticised the protocol for being restricted to children who had convulsions lasting half an hour. It was pointed out to him by Mr Machin that the guidelines referred to convulsions with a total duration of more than half an hour, a convulsion of whatever length followed by a coma lasting two hours or more, or by paralysis or other neurological signs not previously present lasting 24 hours or more. Professor Stewart agreed that his bald statement was incorrect and needed qualification. He also conceded that he had said in a deposition that the controls used in the study were children admitted to hospital with other illnesses when in fact they were community controls. He did not know how he had come to make such an error. Asked by Mr Machin whether it was possible that he was so obsessed with the idea that pertussis vaccine was dangerous that he let his enthusiasm run away with him, he replied that he tried not to and he did not think he had.

In the Tom case, said Mr Machin, he did not understand one thing Professor Stewart had said. He had been asked whether he was aware of any studies suggesting the likelihood of a relation between giving DTP on day $\mathrm{X}$ and seizure activity which occurred 19 days after without any intervening reaction. He had answered: "No systematic study. There are odd cases which fall into that category in the review by Toomey in 1948, by Randolph Byers and Moll in 1948 , and Dr John Wilson and his colleagues in 1974. There is reference to other cases but there is no systematic study of that possibility. There is also reference to the likelihood-and this is a fact to be considered-in the blue report by two independent panels." Professor Stewart admitted that was a wrong recollection of these three papers.

Mr Machin drew Professor Stewart's attention to a sentence in his report prepared for the Kinnear case: "Levine and Wenk described a hyperacute allergic encephalomyelitis which occurred in children who appeared to have been sensitised by a previous dose of pertussis vaccine." Counsel asked Professor Stewart whether he recollected anything about the age or ethnic origin of the children. On checking the reference, Professor Stewart answered that it was an experimental paper on male and female Lewis rats. He said he could have been assuming it was a study in children when in fact it was a study in animals. In the context mentioned here, he said he was looking at alternative mechanisms and he was mentioning the use of hypersensitivity, which he perhaps wrongly assumed was done in children, but it might be said there was some other reference which should have been put in.

\section{Professor Stewart accepted that he is in a minority}

Professor Stewart agreed that there was no distinct clinical syndrome in pertussis vaccine associated cases that distinguished them from cases not associated with the vaccine. He agreed that the mere fact that awards were made under the Vaccine Damage Payments Act was no indication that pertussis vaccine caused brain damage, because it was an assumption of the legislature in passing the Act that the vaccine can cause brain damage.

He also accepted that in his views about pertussis vaccine, he was in a minority among his peers. It was impossible for him, he said, to make headway with the appropriate committees, and his papers had been turned down for publication. He had given interviews to the press because he felt that this was a public health risk and an unjustifiable risk because the vaccines were not all that effective. He was the patron of a Virginia based society called "Distressed Parents Together" (from the initials DPT, which is the American equivalent of DTP). There was a danger of becoming obsessive, he realised, but he had tried to avoid it.

Bellman, who had taken part in the encephalopathy study and written a thesis on whooping cough and the vaccine, had said the encephalopathy study was the only investigation performed to date that has provided an epidemiologically valid analysis, and that an association of two events in time could not be accepted as evidence of a causal relationship without adequate clinical information and control data; Professor Stewart agreed with these statements. In order to get any kind of estimated relative risk or attributable risk you must have a study with controls.

When Mr Machin drew his attention to it, Professor Stewart accepted that he had made a number of errors in calculation in interpreting Ström's data. He agreed that he was purporting in his report to derive convulsion figures over stated intervals for the three years 1962-4 when there was no way of deriving these figures from the data in the paper. Only one of the studies he had quoted, the study by Cody and Baraff, showed statistically an appreciably higher figure for convulsions after DTP than the background figure of 1 in 12000. Professor Stewart said he agreed with Dr Bellman that the cohort studied was unsatisfactorily small (15752) for a prospective study looking for rare disorders.

He agreed that there was no evidence in the North West Thames series, embracing large numbers of children, of any explosive encephalopathy syndrome of the Byers and Moll type. It puzzled him that in all the Public Health Laboratory Service's series there was no such occurrence. The encephalopathy study also disclosed nothing of the kind.

Mr Justice Stuart Smith asked Professor Stewart whether it was now correct that the only one of the studies considered which supported the thesis that the frequency of convulsions after DTP was higher than the background frequency of 1 in 12000 was the study by Cody and others. He replied that that was so but that he would like to recalculate the figures and come back to the matter later. He said he would not challenge the conclusion reached by the encephalopathy study that there was no statistically significant relationship between infantile spasms and pertussis vaccine. He also agreed that there was nothing in the studies which proved a statistically significant connection between DTP and sudden infant death syndrome, but the possibility of a contributory role in a multifactorial situation could not be excluded.

When he had had an opportunity of looking at the studies again, Professor Stewart added to his evidence on the frequency of convulsions. He said that recalculating the figures in Ström's study to take account of the fact that the vaccination was given on each of three occasions would give a mean figure of something like 1 in 10000 and a range between 1 in 7000 or 8000 and 1 in 15000 or 18 000. Re-examined by $\mathrm{Mr}$ Priest he said he also had some doubts about Mr Machin's calculation of the frequency of convulsions in the MRC/PHLS trials. One possible method of calculation would produce a figure of 1 in 4276. With regard to Ström's study, dividing the denominator by the number of children we knew had convulsions within the first 24 hours would give a frequency of 1 in 9000 reactions within 24 hours, assuming each child had only one injection. He said he was also doubtful about the figure of 1 in 44000 from the Pollock study. As a single cluster event it should be 1 in 12000 for children requiring admission to hospital within 24 hours or, for children having recurrent convulsions, 1 in 17000.

Concluding his evidence, Professor Stewart said, in answer to a question by $\mathrm{Mr}$ Priest, that if asked whether it was more likely than not that DTP could cause permanent brain damage, his answer would be, "Yes." If it continues the trial is expected to last another four or five months. If legal aid is withdrawn the whole issue of whether whooping cough vaccine causes brain damage will have to be debated all over again in another case. 